\title{
Masson's Assault on Truth: A Critique
}

Emmanuel E. Garcia, MD

Institute of Pennsylvania Hospital, Philadelphia

Follow this and additional works at: https://jdc.jefferson.edu/jeffjpsychiatry

Part of the Psychiatry Commons

Let us know how access to this document benefits you

\section{Recommended Citation}

Garcia, MD, Emmanuel E. (1987) "Masson's Assault on Truth: A Critique," Jefferson Journal of Psychiatry. Vol. 5 : Iss. 1 , Article 8.

DOI: https://doi.org/10.29046/JJP.005.1.006

Available at: https://jdc.jefferson.edu/jeffjpsychiatry/vol5/iss1/8

This Article is brought to you for free and open access by the Jefferson Digital Commons. The Jefferson Digital Commons is a service of Thomas Jefferson University's Center for Teaching and Learning (CTL). The Commons is a showcase for Jefferson books and journals, peer-reviewed scholarly publications, unique historical collections from the University archives, and teaching tools. The Jefferson Digital Commons allows researchers and interested readers anywhere in the world to learn about and keep up to date with Jefferson scholarship. This article has been accepted for inclusion in Jefferson Journal of Psychiatry by an authorized administrator of the Jefferson Digital Commons. For more information, please contact: JeffersonDigitalCommons@jefferson.edu. 


\title{
Masson's Assault on Truth: A Critique
}

\author{
Emanuel E. Garcia, M.D.
}

In his book, The Assault on Truth, J. M. Masson (1) proposes to challenge the very foundations of psychoanalysis by showing how Freud's abandonment of the so-called seduction theory of the etiology of neurosis was erroneously predicated.

Masson's argument, in essence, may be summarized as follows. Freud, while studying with the eminent neurologist Charcot in Paris (from October 1885 to February 1886), found himself exposed to the prevalent horrors of child abuse, which were copiously detailed in the French medical literature at the time, and which were very probably demonstrated to him at the Paris morgue. The impression of these revelations would contribute profoundly to Freud's formulation of his seduction theory of the etiology of the neuroses in a trio of papers published in 1896.

Masson's interpretation of this theory is that a sexual act of cruelty and violence perpetrated by an adult upon an unwilling child represents the fundamental cause of every neurosis. Freud's emphasis is purportedly on realistic external factors in the genesis of mental illness.

Culling data from Freud's correspondence with otorhinolaryngologist Wilhelm Fliess, Masson presents an elaborate scenario upon which he bases his case. The principals are Freud, his friend Fliess, and Emma Eckstein. Eckstein, at approximately 27 years of age, undertook analysis with Freud. She apparently suffered from painful and irregular menstruation, which Masson speculates Freud attributed to masturbation. This might have partially explained Freud's having recruited friend Fliess's aid. According to Masson, Fliess believed that masturbation caused dysmenorrheic symptoms and also led to a transformation of the left middle turbinate in the nose. He advocated abstinence and surgical removal of the altered nasal structure.

Freud was hesitant to entrust the nasal surgery to Fliess alone. Masson notes Freud's recommendation that a senior Viennese surgeon, Robert Gersuny, assist Fliess. Freud nevertheless overcame his doubts and allowed Fliess to operate on his own in February 1895.

The results were far from satisfactory. As it turned out, Fliess inadvertently left half a meter of iodoform gauze in the nasal cavity, which became the cause of Eckstein's seemingly inexplicable pain, edema, and bleeding after the procedure. It was the Viennese surgeon Rosanes who discovered this oversight while

Dr. Garcia is a first-year resident at the Institute of Pennsylvania Hospital, Philadelphia, Pennsylvania. 
investigating, at Freud's request, Eckstein's post-surgical complaints. Unfortunately, the surprise of this discovery must have caused a suspension of critical medical judgment. Unthinkingly, Rosanes withdrew the gauze and a massive hemorrhage ensued. Eckstein went temporarily into shock, but recovered after Rosanes repacked the nasal cavity with fresh gauze to effect hemostasis. The day after, Rosanes and Gersuny together repeated the operation under controlled conditions.

All was not well, however, and ten days after the second operation, the pain, swelling and hemorrhages returned. Eckstein's nose was packed again, but bleeding continued to occur sporadically nevertheless. Several months later she experienced another massive hemorrhage as the packing was being removed. Freud, gloomy and shaken, ventured to sound a reproachful note in his letters to Fliess, but this was quickly drowned by renewed protestations of allegiance and confidence. Presumably, Fliess' continued friendship was all-important.

Fliess explained Eckstein's hemorrhages as manifestations of a biological periodicity which was wholly independent of any actual external trauma. This explanation was in accordance with certain numerological hypotheses he was then elaborating. Masson contends that Freud, wanting to protect his friend from any culpability, turned away from implicating Fliess' operative error as the immediate cause of Eckstein's bleeding. Masson highlights Freud's later claim that Eckstein "bled out of longing ... as an unfailing means of rearousing my [Freud's] affection”' (p. 101).

Believing that Eckstein herself was the patient who inspired Freud to formulate the seduction theory in the first place, Masson asserts that Freud's attribution of Eckstein's hemorrhages to sexual fantasy, rather than to the reality of the operation's trauma, ultimately extended to her accounts of childhood seduction. Freud came to consider these accounts as fantasies rather than real events. This, in effect, marked Freud's renunciation of the seduction hypothesis, the rewards for which would be an end to his ostracism by the medical establishment for having acknowledged the reality of the sexual abuse of children, as well as a continuation of his friendship with Fliess.

Masson levels an eloquent attack on Freud and his "science":

... by shifting the emphasis from an actual world of sadness, misery, and cruelty to an internal stage on which actors performed invented dramas for an invisible audience of their own creation, Freud began a trend away from the real world that, it seems to me, is at the root of the present-day sterility of psychoanalysis and psychiatry throughout the world. (p. 144)

Furthermore, he claims that the survival of psychoanalysis is made possible only by a conspiracy of its adherents to suppress the truth about its origins in Freud's fateful false step, in a stubborn refusal to acknowledge the real traumas at the heart of mental illness. The analytic setting, with its implacable deprecation of reality and exaltation of fantasy, merely subjects patients to a repetition of the 
traumatic abuse suffered in childhood. Thus, for Masson, even such timehonored concepts as transference and the unconscious must be meaningless.

A comprehensive examination of Freud's seduction theory is obviously beyond our scope here, but a brief account is required to address Masson's argument.

In three papers published in 1896 (2-4), Freud promulgated the view that in each of the neuroses he had analyzed (hysterical, obsessional, or mixed hysteriaobsessional), accounts of seduction were reported to which the symptoms of the neurosis could be traced. Freud regarded these as actual memories. The seductions consisted of an excitement of the genitals, a coitus-like process, the memory of which exerted the traumatic pathological effect. The seductions, which were thought to occur before the ages of eight to ten, were presumably submitted to with indifference or a little fright. Freud boastfully regarded the discovery of this distal etiologic event as a caput Nili of neuropathology. He asserted that the seductions were perpetrated not only by adults, but by children as well, a point Masson neglects to mention. Freud explained the active sexuality of these children by postulating that they had previously been seduced.

At the time, Freud's conception of the psychological capabilities of children and of their sexual life was quite restricted, in keeping with the prevailing assumptions of the day: children were passive, incapable of fantasy, and asexual unless subjected to the provocation of a seduction. The so-called abandonment of the seduction theory was occasioned by Freud's finding, to the best of his abilities and without change in methodology, that in one case the reported seduction never took place. Consequently, he was forced to conclude:

If hysterical subjects trace back their symptoms to traumas that are fictitious, then the new fact which emerges is precisely that they create such scenes in phantasy, and this psychical reality requires to be taken into account alongside practical reality. This reflection was soon followed by the discovery that these phantasies were intended to cover up the autoerotic activity of the first years of childhood, to embellish it and raise it to a higher plane. And now, from behind the phantasies, the whole range of a child's sexual life came to light (5) (pp. 17-18).

It must be noted that, contrary to the impression given by Masson, Freud never renounced his belief in either the occurrence of seductions or their contribution to neurosogenesis. Many years after he modified his earlier theory, Freud explicitly labeled seduction a "common" phenomenon $(6,7)$, and cautioned that "phantasies of being seduced are of particular interest, because so often they are not phantasies but real memories" (8) (p. 370).

In his famous case history of the Wolf-Man, Freud even devoted an entire chapter to the consequences of his patient's seduction (9). These facts can hardly be reconciled with Masson's picture of a man who denied and disregarded the importance of "external reality" on psychological development. 
Seductions occur, as Freud clearly recognized, but they do so in the context of the natural developmental unfolding of childhood sexuality. Adherence to a belief in the necessity of seduction for neurosogenesis would have been "fatal" for psychoanalysis only insofar as it would have prevented the psychoanalytic investigation of infantile sexuality. As Freud (10) wrote:

When the mistake had been cleared up, the path to the study of the sexual life of children lay open. It thus became possible to apply psycho-analysis to another field of science and to use its data as a means of discovering a new piece of biological knowledge. (p. 35)

Before addressing the relevance of Masson's material to his assertions about the invalidity of psychoanalysis, I must caution the reader that the above account by no means does justice to the complexities of the seduction theory and its role in Freud's thought. Please see E.E. Garcia for a much more comprehensive discussion (11).

Whether or not Freud was the fraudulent and unscrupulous opportunist depicted by Masson is immaterial to an objective assessment of psychoanalytic concepts. The merit of scientific ideas remains independent of the forces, however bizarre, which lead to their expression. Issues of character and personal motivation are simply irrevelant. Even if his entire reconstruction can be accepted without dispute, Masson's claims to have debunked psychoanalysis are fundamentally untenable. His argument is ad hominem; nowhere does he attempt to present an examination of the scientific evidence for or against the seduction theory or Freud's later hypotheses about the etiology of the neuroses. Certainly no serious investigator would attempt to discredit Newton's laws of motion by assailing the mathematician's character-why should Freud and his work be an exception to implicit acknowledgment of the distinction between a man's life and his scientific discoveries?

Furthermore, Masson's almost exclusive reliance on Freud's private correspondence and personal notes must be questioned. An immersion into the intentionally unpublished material at the expense of the intentionally published may easily lead an investigator astray. What misgivings, contradictions, renunciations and reacceptances - in short, the mind's flux - are not the daily staple of any working scientist? It would certainly be a difficult enough task to derive from the daunting complexity of Einstein's personal notes on general relativity a genuine aid to the understanding of the published presentation of the theory.

The act of deliberately placing one's data before the world's eyes in the form of publications, as Freud did, bespeaks an invitation to the scientific community to assess their merit. Only if one is attempting to chart the tortuous paths by which scientific hypotheses come into being, with the aim thereby to reveal something about the psychology of genius or creativity, are a person's private musings of consequence. On no account should they supersede published works as the material to be appraised for merit. For example, as fascinating as the private speculations of a molecular geneticist may be, one need 
only to look to the public record to evaluate the validity of his findings. If the methodology and the experiments seem impeccable, then one comes to accept a researcher's conclusions, albeit, as with all scientific endeavors, rather tentatively, and ever on the lookout for confirming or disconfirming data.

Although the force of a scientist's personality may sometimes quench the critical spirit of coworkers and students, it is highly unlikely that such an effect would extend decades after his death and obscure his major errors. Occasionally, a fraudulent investigator may suppress, disguise, or distort data, but such misrepresentation does not go undetected for long. Science is never the work of one man alone, even if he is a genius of the highest magnitude.

In summary, as riveting a tale as Masson's may be, we are nevertheless compelled to conclude that it has no bearing on the scientific issues with which psychoanalysis concerns itself, owing to the inherent invalidity of ad hominem arguments. Furthermore, Masson's case is weakened by his misunderstanding of Freud's views on seduction and external reality, of the essence of the seduction theory as Freud formulated it.

Finally, the imposing challenge of integrating the events of Freud's personal life with the development of his ideas, in addition to assessing the accuracy of Masson's characterological data, remains to be met. In my opinion, it would be most fruitfully undertaken by a psychologist of genius possessing not only the requisite skills for historical investigation, but also a thorough understanding of psychoanalysis.

\section{REFERENCES}

1. Masson JM: The Assault on Truth. Farrar, Straus and Giroux, 1984

2. Freud S: Heredity and the aetiology of the neuroses. Standard Edition, 3:141-156, 1896a

3. Freud S: Further remarks on the neuro-psychoses of defence. Standard Edition, $3: 162-185,1896 \mathrm{~b}$

4. Freud S: The aetiology of hysteria. Standard Edition, 3:191-221, 1896c

5. Freud S: On the history of the psycho-analytic movement. Standard Edition, 14:7-66, 1914

6. Freud S: Female sexuality. Standard Edition, 21:225-243, 1931

7. Freud S: An outline of psycho-analysis. Standard Edition, 23:144-207, 1940

8. Freud S: Introductory lectures on psycho-analysis. Part III. Standard Edition, 16:241-463, 1917

9. Freud S: From the history of an infantile neurosis. Standard Edition, 17:7-122, 1918

10. Freud S: An autobiographical study. Standard Edition, 20:7-74, 1925

11. Garcia EE: Freud's seduction theory. Psychoanal Study Child, vol. 42 (in press) 